\title{
Uma Abordagem para Gestão de Avaliações de Ensino Baseada em um Jogo Interativo de Tabuleiro: o Ludo Educativo Atlantis
}

\section{Alternative Title: An Approach to Manage Evaluations Using an Interactive Board Game: The Ludo Educational Atlantis}

\author{
Thiago Jabur \\ Bittar \\ UFG Catalão \\ thiagojabur@ufg.br
}

\author{
Luanna Lopes \\ Lobato \\ UFG Catalão \\ luannalobato@ufg.br
}

\author{
Leandro Agostini do \\ Amaral \\ USP ICMC \\ leandroagostini@usp.br
}

\author{
Elson \\ Longo \\ INCTMN - UNESP \\ elson@iq.unesp.br
}

\begin{abstract}
RESUMO
$\mathrm{O}$ uso de jogos digitais para apoio educativo podem motivar os alunos, mas esse uso deve ser bem explorado para o sucesso pedagógico, abordando os conceitos vistos em sala de aula. Assim, este trabalho apresenta considerações e resultados na criação e teste de Ludo Atlantis para a Educação, que é um sistema de jogos digitais educacionais, em que os alunos do ensino fundamental podem participar de um jogo de tabuleiro eletrônico. Desafios são apresentados sob a forma de perguntas e respostas definidas por um professor responsável. Para a validação inicial, o jogo foi utilizado em uma Escola Estadual de São Carlos-SP, em uma disciplina de ciências, sendo relatado neste trabalho as considerações e os resultados dessa experiência.
\end{abstract}

\section{Palavras-Chave}

Jogo, tabuleiro, gamificação, educação, avaliações.

\begin{abstract}
The use of digital games for educational support can motivate students, but this use should be well exploited for pedagogical success, behaving as allies in the conventional process, addressing the concepts seen in the classroom. Thus, this paper presents considerations and results on the creation and testing of Ludo Educational Atlantis, which is an educational digital game system, in which students of elementary school can participate in an electronic board game. It challenges are presented in the form of questions and answers defined by a responsible teacher who can monitor the results of their students. For initial validation, the game was used in a State School of São Carlos-SP, in a Science discipline, being reported in this paper the considerations and results from this experience.
\end{abstract}

\section{Categories and Subject Descriptors \\ K.3.1 [Computer Uses in Education]}

\section{General Terms}

Design, Experimentation, Human Factors.

Permission to make digital or hard copies of all or part of this work for personal or classroom use is granted without fee provided that copies are not made or distributed for profit or commercial advantage and that copies bear this notice and the full citation on the first page. To copy otherwise, or republish, to post on servers or to redistribute to lists, requires prior specific permission and/or a fee.

SBSI 2015, May 26-29, 2015, Goiânia, Goiás, Brazil.

Copyright SBC 2015

\section{Keywords}

Game, board, gamification, education, evaluations.

\section{INTRODUÇÃO}

Um dos desafios vivenciados pelos professores em seu cotidiano é o de realizar avaliações dos conteúdos ministrados, de modo que essas sejam bem vistas e proveitosas para os alunos e, ainda, eficientes para medir a qualidade do que foi ensinado e, efetivamente, aprendido. Comumente são utilizadas questões para avaliação de modo não interativo, que pode fazer com que os alunos se sintam pressionados e não atraídos pelo método de avaliação. Porém, esta ainda é uma atividade essencial para se medir e analisar o aprendizado, a qual é amplamente utilizada.

Assim, novos métodos devem ser investigados para tornar as avaliações mais agradáveis, modernas, eficazes e eficientes em que diferentes estratégias podem ser utilizadas. Como exemplo de tais estratégias, nesta pesquisa é proposto e utilizada uma abordagem com base no uso de um Jogo Digital Interativo.

Já há muito tempo, antes dos Jogos Digitais ganharem tamanha força no mundo cibernético, Crawford (1982) relata que todo tipo de jogo faz com que o jogador possa expandir conhecimentos e experiências [1]. E também é apropriadamente citado que com a busca do prazer, divertimento e a fuga do cotidiano, a necessidade de aprender e conhecer são fatores que levam a pessoa a ser um adepto aos jogos.

Adicionalmente, os Jogos Digitais, mais recentemente, têm sido aplicados em diversas áreas, ampliando seu principal foco de atuação, que inicialmente visava mais o entretenimento. Assim, foram incluídas novas aplicações para os jogos além do entretenimento puro e simples, com usos mais diversificados, voltadas principalmente para a educação. Desse modo, no contexto escolar, o uso de jogos como parte do processo de ensino e aprendizagem, incluindo uso nas avaliações, pode auxiliar no envolvimento dos alunos, incluindo séries iniciais, e tornar a sala de aula e o ensino mais diversificado e dinâmico.

De acordo com Lucchese e Ribeiro (2012) [2], o principal objetivo dos Jogos Digitais Educacionais não é desafiar os participantes e sim ter mecanismos para que o jogador possa se desenvolver física e mentalmente. Segundo McClarty, Frey e Dolan (2012) [3] não apenas a diversão é uma parte importante do desenvolvimento saudável de uma criança, os jogos permitem que as crianças aprendam por meio de brincadeiras imaginárias. Jogos Digitais vão ainda além ao apresentarem a oportunidade das 
brincadeiras serem parte de um ambiente simulado e, portanto, não são necessariamente distrações ao aprendizado.

É certo que os Jogos Digitais Educacionais não podem educar por si só, assim a proposta deste trabalho está relacionada ao uso de uma abordagem como auxílio inicial a práticas educacionais que podem ser utilizadas em escolas, organizações e até mesmo no dia a dia.

Nesse sentido, neste artigo é apresentada uma abordagem de gestão de avaliações de ensino com uso do Ludo Educativo Atlantis. Este, por sua vez, é um sistema educacional, em que alunos do Ensino Fundamental e Médio participam de um jogo eletrônico em formato de tabuleiro, onde os desafios são apresentados sob a forma de perguntas e respostas, as quais devem ser, previamente, definidas pelo professor responsável pela disciplina.

Com vistas a coletar dados reais e, considerando os aspectos cognitivos que devem ser respeitados e verificados com a aplicação de um Jogo Educacional, neste trabalho tem-se uma análise prática do estudo. Para tanto, o jogo foi utilizado em uma Escola Estadual de São Carlos-SP na disciplina de Ciências, sendo reportados os resultados advindos dessa experiência, tendo assim, para validação inicial, resultados compostos por dados empíricos coletados por meio de um Estudo de Caso, efetivamente desenvolvido e aplicado seguindo as recomendações de Runeson e Höst (2009) [4].

O restante deste artigo está organizado do seguinte modo: na Seção 2 é explicitada a potencialidade dos Jogos Digitais Educacionais e a gamificação. Na Seção 3 são apresentados o histórico, contextualização e justificativas. Já na Seção 4 é apresentada uma análise de trabalhos relacionados, para que sejam vistas as inovações do jogo em questão e, em seguida, na Seção 5, tem-se a metodologia de pesquisa utilizada. Na Seção 6 é apresentado o desenvolvimento do trabalho, em que é descrito o projeto, seus módulos e componentes, bem como seu funcionamento e principais resultados obtidos com a aplicação em sala de aula (Seção 7). Por fim, são apresentadas as conclusões na Seção 8.

\section{JOGOS DIGITAIS EDUCACIONAIS}

De acordo com Juul (1998) [5], Jogos Digitais são representados em um nível mais abstrato, com recursos computacionais. Sendo que a principal característica que distingue Jogos Digitais dos que são conceituados de forma mais ampla, como os jogos sem interferência de aspectos computacionais, é a existência de mundos fictícios. Esses mundos são delimitados por recursos computacionais e não são tão imaginários como os não digitais que possuem isso como recurso maior.

Devido à crescente aceitação dos jogos digitais, seja para fins de entretenimento ou educacional, a complexidade destes jogos tende também a aumentar, seja em relação a aspectos técnicos envolvendo o desenvolvimento, por parte do desenvolvedor, ou em relação à jogabilidade, por parte do jogador, referente a níveis e fases cada vez mais difíceis de serem ultrapassadas. Neste sentido, bases teóricas devem ser apresentadas para, de modo a melhorar o design dos jogos, desde sua prototipação até sua proposta final de desenvolvimento.

De todos os tipos de jogos, Crawford (1982) evidencia quatro elementos fundamentais: representação, interação, conflito e segurança [1]. A representação é estabelecida de acordo com o que jogo se aproxima a simulação da realidade, ou seja, mesmo com que o jogo haja uma representação simples e subjetiva, devese haver traços da realidade para aproximá-lo ao mundo real. A interação é quando o jogador é capaz de modificar a representação que lhe é proporcionada e verificar a resposta, que são as consequências de sua interação. O conflito é determinado pelos desafios distribuídos nos jogos que tornam o objetivo deles algo que não seja facilmente alcançado. A segurança oferece ao jogador um modo de que possa ser aproveitada a representação dada sem correr riscos maiores, como em jogo de simulação de guerra onde não há perigos físicos. Diante de tais definições é possível definir o que são os jogos de uma forma ampla, porém, é preciso ter atenção a sua aplicabilidade para que estes não sejam substituídos pelos métodos tradicionais, principalmente quando envolve a educação.

Neste sentido, o jogo educacional pode ser definido como um instrumento onde o que o jogador aprende, seja relações de causa e efeito ou fatos concretos ou abstratos, devem ser aplicáveis ou relevantes fora do contexto do jogo e, portanto, não servem apenas para melhorar o desempenho dentro do jogo, mas também pode ser um meio para inseri-lo com qualidades na sociedade [6]. Assim, o jogador não deve apenas aprender estratégias de jogo, mas também assimilar aspectos educacionais que podem ser utilizados durante seu cotidiano.

Nessa mesma linha, a gamificação pode ser definida como o processo de enriquecimento de serviços por meio de ações e possibilidades que remetem a experiências de jogos (HAMARI, KOIVISTO e SARSA, 2014). Com frequência cada vez maior, esse conjunto de técnicas tem sido aplicado por empresas e entidades de diversos segmentos como alternativas às abordagens tradicionais, sobretudo no que se refere a encorajar pessoas a adotarem determinados comportamentos, a familiarizarem-se com novas tecnologias, a agilizar seus processos de aprendizado ou de treinamento e a tornar mais agradáveis tarefas consideradas tediosas ou repetitivas. Nos últimos anos, principalmente, game designers de diversas partes do mundo têm se dedicado a aplicar princípios de jogos em campos variados, tais como saúde, educação, políticas públicas, esportes ou aumento de produtividade (VIANNA et al., 2013).

Se por um lado a gamificação incorpora elementos de jogos a sistemas tradicionais, de ensino ou não, os Jogos Educacionais se beneficiam muito da implementação da gamificação. De acordo com Schuytema (2008), os Jogos Digitais são divididos em três partes: enredo, motor e interface interativa. O enredo é o que define como e quais acontecimentos irão surgir de acordo com as interações com o jogador. O motor é o mecanismo do jogo, onde o jogador pode alterar o ambiente e definir suas ações através de decisões. A interface interativa é como um caminho de entrada para o jogador poderá interagir com o jogo.

Tendo em vistas os vários benefícios decorrentes da utilização de Jogos Digitais, pode ser mencionado que tais jogos apresentam metodologias inovadoras e criativas sendo facilmente aceitos por jovens e crianças com vontade de aprender de forma divertida. Porém, o maior desafio na aplicação de Jogos Digitais Educacionais é a proporção da diversão, a qual é uma característica fundamental de um Jogo Digital.

Neste sentido, o Ludo Educativo Atlantis, além de um jogo educativo, precisa incorporar elementos de gamificação para engajar os alunos em sua utilização e, ainda, considerar aspectos 
pedagógicos de modo a garantir a qualidade do que é ensinado pelo professor, bem como do que é aprendido pelo aluno.

\section{HISTÓRICO E JUSTIFICATIVAS}

Quando a maior parte dos educadores e pais pensam sobre jogos eles demonstram preocupação sobre o uso destes entre os mais jovens, principalmente acerca dos excessos por parte de alguns jogadores ou de temáticas violentas de alguns títulos (ARANDA e SANCHEZ-NAVARRO, 2008). Apesar dessas preocupações, a inserção de Jogos Digitais na sociedade já está concretizada a mais de uma década, sendo uma realidade atual que não para de crescer, constituindo uma poderosa indústria que está continuamente evoluindo suas aplicações tecnológicas (AGUILERA e MÉNDIZ, 2003).

Foi pensando nessa lacuna entre gerações que foi proposto o projeto Ludo Educa Jogos em 2010. Inicialmente, apenas com um jogo de Sudoku eletrônico de elementos químicos, os projetos foram crescendo em ambição e foi desenvolvido o jogo de tabuleiro chamado de Ludo Educativo. Neste, o professor pode acompanhar seus alunos, na sala de aula ou em casa, enquanto eles participam de um jogo de tabuleiro. Cada casa destinada a um aluno apresenta uma pergunta e o aluno somente chega ao final do jogo respondendo as perguntas de modo correto. A cada resposta correta são adicionados 5 pontos aos pontos do aluno e para resposta incorreta são subtraídos 2 pontos.

Com o passar do tempo, o Ludo Educativo cresceu em importância e se tornou o nome da equipe envolvida com o projeto, tendo sido feito o lançamento do Portal Ludo Educativo, contando com a incorporação de novos Jogos Educacionais, não apenas de tabuleiros. O principal objetivo de trabalho da equipe é aliar pesquisa ao desenvolvimento, aproximando a Universidade e a sociedade, por meio da integração de professores, desenvolvedores e pesquisadores, com envolvimento de mestres e doutores nas áreas de computação e educação.

Neste sentido, entende-se que os aspectos relacionados às práticas educacionais e pedagógicas devem ser considerados para o projeto e, assim, foram introduzidos a este trabalho questões realmente eficientes do ensino. Para tanto, uma consulta a profissionais da área da educação foi realizada, objetivando identificar pontos relevantes e necessários para uma proposta de gestão eficiente de avaliações de ensino, visando a descoberta de resultados relevantes em relação ao ensino e aprendizado.

Em relação aos aspectos técnicos, manutenções e atualizações foram também necessárias ao projeto inicialmente desenvolvido, uma vez que as tecnologias dos tabuleiros do Ludo Educativo se tornaram obsoletas. Isso já era de se esperar em relação a projetos envolvendo a Computação, uma vez que os avanços tecnológicos são constantes. Como exemplo, pode-se citar o fato de que o Adobe Flash, da maneira como foi utilizado para o desenvolvimento dos tabuleiros originais, não permitia o uso de tecnologias modernas, como o HTML5 e a migração para dispositivos móveis.

Além disso, a equipe era constantemente procurada por professores com dois pedidos recorrentes: i) novas ideias de tabuleiros, com temáticas específicas para sua disciplina; ii) as questões não se encaixavam com a matéria dada pelo professor, por serem mais avançadas ou mais básicas que as presentes no banco de questões ou mesmo por nem existirem questões sobre o assunto desejado.
Além das dificuldades técnicas, era necessário procurar soluções conceituais que solucionassem os pedidos dos professores. Assim foi pensado em uma abordagem de avaliação utilizando um sistema de geração de jogos, onde tanto o aluno como o professor influenciam e alteram o jogo, ainda utilizando tabuleiros. Esse sistema é parecido com o utilizado em jogos de RPG (RolePlaying Game) e popularizado pelo HeroQuest.

\section{Trabalhos Relacionados}

Nesta seção é apresentada uma revisão de trabalhos relacionados e são também abordadas as principais tecnologias utilizadas no desenvolvimento do projeto em questão.

A metodologia de busca de trabalhos relacionados envolveu o uso das máquinas de busca ACM Digital Library e Google, sendo que o uso desta última opção permitiu que não só trabalhos acadêmicos fossem resgatados, ampliando o escopo para encontro de portais que hospedam jogos variados. A expressão de busca usada envolveu os seguintes tokens: "jogo", "game", "educativo", "educação", "tabuleiro" e "perguntas".

Vale ressaltar que esta é uma pesquisa ad-hoc, o que difere de uma pesquisa feita utilizando a metodologia de Revisão Sistemática da Literatura, proposta por Kitchenham e Charters (2007).

Como resultado, foram encontrados poucos jogos similares a este trabalho, sendo analisados apenas aqueles com foco educativo. Com a escassez de resultados, foi feita a opção de não se limitar por plataforma (sendo vistos jogos para Web e para dispositivos móveis) e isso permitiu uma análise da tendência cada vez maior de se ter jogos multi-plataforma. Os principais elementos e resultados identificados com a pesquisa são analisados nas próximas subseções.

\subsection{Ludo Primeiros Passos}

O jogo Ludo Primeiros Passos está disponível na Web, tendo sido desenvolvido pelo Grupo Ludo Educativo, com o objetivo de auxiliar na alfabetização, trabalhando com desafios que envolvem letras, palavras e sílabas, como pode ser visto na Figura 1.
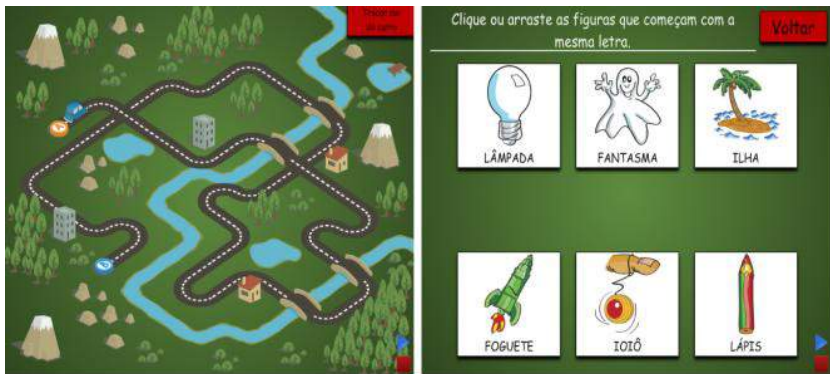

Figura 1 - Jogo Ludo Primeiros Passos

Como elementos do cenário tem-se uma estrada em meio a árvores e construções. Houve uso intensivo de cores diversas, sendo que isso foi feito pensando no público de crianças na fase de aprendizado de sílabas e palavras. A tecnologia utilizada foi a Adobe Flash, com acesso pela $\mathrm{Web}^{1}$. A mecânica do jogo foi pautada na simplicidade e envolvimento contínuo do jogador, que vai avançando de casa em casa, com o sucesso nos desafios.Cada um desses desafios é formado por pequenos e diferentes jogos, em que é necessário, por exemplo, ligar sílabas para formar uma

\footnotetext{
${ }^{1}$ http://portal.ludoeducativo.com.br/pt/play/ludo-primeiros-passos
} 
palavra, de acordo com sua imagem relacionada. Atualmente existem mais de 180 imagens no jogo, que garantem diversas variações de desafios para o jogador, a partir de uma seleção aleatória das mesmas.

\subsection{ChallengeBoard}

$\mathrm{O}$ jogo ChallengeBoard ${ }^{2}$ foi desenvolvido para manter a nostalgia viva dos jogos de tabuleiro, trazendo esse formato para tablets na plataforma iOS, como pode ser visto na Figura 2.

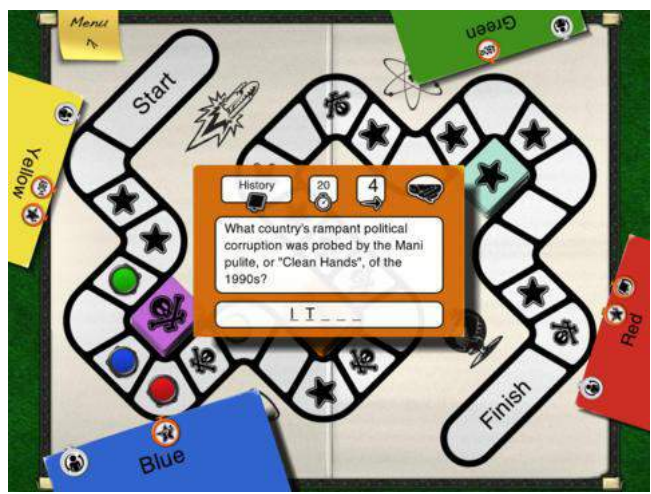

Figura 2 - Jogo ChallengeBoard

Sua aplicação é dinâmica e o jogador deve responder a cartas de perguntas sobre vários temas para avançar no percurso do tabuleiro. Para fazer download do jogo é cobrado 2,99 dólares. Um interessante recurso que foi implementado no ChallengeBoard é a presença de múltiplos personagens, sendo cada um representado por uma cor, fazendo uma analogia aos jogos de tabuleiros físicos convencionais. Como o tablet pode ter a interação compartilhada por vários usuários, por alternância de uso, sem a necessidade de conexão entre vários dispositivos, a dinâmica do jogo não foi prejudicada.

\subsection{Viagem Através do Conhecimento}

O Jogo Viagem Através do Conhecimento ${ }^{3}$ aborda conhecimentos gerais para usuários maiores de 12 anos. O objetivo é simples, partindo da posição onde está o personagem,deve-se chegar ao extremo oposto do tabuleiro, como pode ser visto na Figura 3.

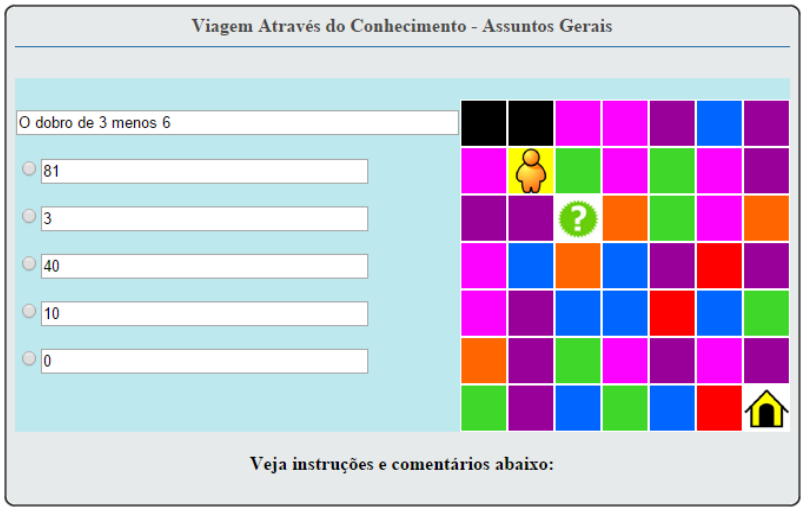

Figura 3 - Jogo Viagem Através do Conhecimento

${ }^{2}$ https://itunes.apple.com/br/app/challenge-board-game/id388837767

${ }^{3}$ http://sitededicas.ne10.uol.com.br/jogos/conhecimento/jogos_onl ine_conhecimento.htm
Para chegar ao final do jogo é necessário responder as perguntas que surgem à medida que o jogador clica sobre uma das casas coloridas. Para terminar o jogo mais rápido, com menos perguntas, o usuário deverá caminhar na diagonal, essa estratégia é um tanto óbvia e poderia ser mais bem trabalhada no enredo.

\section{Análise Comparativa}

A partir do estudo dos trabalhos relacionados, descritos nas subseções anteriores, para facilitar uma análise comparativa sintética, é apresentada a tabela a seguir. Para tanto foram escolhidos 4 critérios de verificação como mostrado na Tabela 1.

Tabela 1 - Análise comparativa de Jogos Educativos de tabuleiros

\begin{tabular}{|l|l|l|l|l|l|}
\hline & Jogo & Web & Mobile & $\begin{array}{l}\text { Área do } \\
\text { professor }\end{array}$ & $\begin{array}{l}\text { Separação } \\
\text { em níveis }\end{array}$ \\
\hline 1 & $\begin{array}{l}\text { Viagem Através } \\
\text { do Conhecimento }\end{array}$ & Sim & Não & Não & Não \\
\hline 2 & Ludo Educativo & Sim & Não & Sim & Sim \\
\hline 3 & ChallengeBoard & Não & Sim & Não & Não \\
\hline 4 & $\begin{array}{l}\text { Ludo Primeiros } \\
\text { Passos }\end{array}$ & Sim & Não & Não & Não \\
\hline
\end{tabular}

Como pode ser visto na Tabela 1, a maioria dos jogos apresentados como trabalhos relacionados são para acesso Web (1 de 4, 25\%), o que deve ser melhorado, já que o acesso a tablets e smartphones está cada vez maior.

Outro ponto que merece destaque é que nenhum desses jogos oferece a opção de cadastro de questões pelo professor, o que permitiria o direcionamento do conteúdo de acordo com o lecionado aos alunos. Também não é feito em nenhum desses o desenho dinâmico do tabuleiro. Tais aspectos são tidos como inovações importantes na implementação do Ludo Educativo Atlantis.

\section{METODOLOGIA DE PESQUISA}

Nesta seção é apresentada a metodologia de pesquisa utilizada para desenvolvimento do trabalho. Assim, são detalhadas as decisões adotadas para fundamentar os argumentos quanto à investigação dos problemas de desenvolvimento do jogo em questão. Nas rotinas de desenvolvimento e aplicação do jogo, incluindo as fases iniciais de levantamento de cenário, existem diferentes análises e resultados que fomentam o caráter científico desejado para um trabalho acadêmico, com aproveitamento de esforços no campo da Ciência e Tecnologia.

\subsection{Materiais e Métodos}

Para a execução desta pesquisa foi necessário determinar materiais e espaço físico, como uma sala mobiliada para acomodar os desenvolvedores e seus instrumentos, a saber: cinco computadores desktop ( $1 \mathrm{com}$ Sistema operacional Mac e $4 \mathrm{com}$ Windows) e um servidor de arquivos e de impressão (com sistema Linux), todos ligados em rede e devidamente preparados com acesso à Internet.

A parte Web foi desenvolvida como um módulo do Portal Ludo Educativo, baseado no framework Symfony 2. O jogo utilizado, que será aqui referenciado apenas por tabuleiro,foi desenvolvido com o ambiente de desenvolvimento de jogos Stencyl (em sua 
versão paga), com o apoio de uma designer gráfica. Além desta designer participaram 4 desenvolvedores, sendo 2 deles graduados e os outros em estágio, todos em cursos relacionados à Computação.

Ao buscar status de classificação de pesquisa, pode-se dizer que a pesquisa está para o tipo exploratória dentre os três tipos de pesquisas existentes que são baseadas por seus objetivos: pesquisas exploratórias, descritivas e explicativas. As pesquisas exploratórias se caracterizam por desenvolverem ideias para o crescimento da ciência ou, até mesmo, para a comprovação de fatos sobre um determinado assunto, de modo que sua estrutura seja bem maleável. Muitas vezes tais pesquisas são estruturadas por estudo de caso ou revisões bibliográficas (DE FIGUEIREDO, 2008).

\subsection{Passos da pesquisa}

A definição dos passos da pesquisa é de suma importância por auxiliar na visualização da estrutura do trabalho. Assim, tem-se uma demonstração do planejamento de atividades organizadas em fases.

Dessa maneira, os passos realizados para alcançar os objetivos deste trabalho, como se pode identificar, passam pela definição do tema e levantamento bibliográfico até o Estudo de Caso, conforme recomendações de Runeson e Höst (2009), sendo eles: 1. Reuniões; 2. Levantamento Bibliográfico; 3. Estudo de trabalhos relacionados; 4. Desenvolvimento do jogo; 5. Aplicação em sala de aula e entrevista com a docente responsável; 6. Tabulação dos dados do experimento realizado; 7. Conclusão do estudo.

No passo 1, foram realizadas reuniões para a definição do tema de pesquisa deste trabalho, definindo a problemática da gestão de avaliação de ensino e como isso poderia ser auxiliado usando questões em Jogos Educacionais, focando-se naqueles de tabuleiros. Em seguida, no passo 2, foi feito um levantamento bibliográfico para verificação do contexto para a busca de dados em material científico relacionado ao tema definido. Já no 3 foram verificados quais são os jogos similares ao contexto desejado e como eles funcionam. Em seguida, do passo 4 ao 7 tem-se as considerações de desenvolvimento do jogo, sua aplicação em sala de aula e as conclusões do estudo.

Em cada passo foram utilizadas técnicas específicas de investigação, sendo essas explicitadas nas seções deste artigo na medida em que forem citadas.

\section{DESENVOLVIMENTO DO TRABALHO}

Nesta seção o projeto é detalhadamente descrito, de modo que seja possível identificar todos os passos da metodologia adotada, bem como os recursos e técnicas utilizados.

$\mathrm{O}$ projeto se baseou em um sistema desenvolvido pela equipe anterior do Ludo Educativo, utilizado até hoje por professores de todo o território nacional, chamado originalmente apenas de Ludo Educativo. Esse sistema consiste em jogos de tabuleiro com perguntas e respostas, abordando matérias de diferentes disciplinas e anos escolares, além de um sistema Web de administração das salas pelos professores. $\mathrm{O}$ sistema pode ser executado por meio da Web, o que lhe confere uma maior portabilidade entre diferentes tipos de plataformas, como Mac OS, Linux e Windows.

Os seguintes componentes principais foram definidos: a visão da perspectiva do aluno (tabuleiro, atividades, perguntas e respostas); a visão da perspectiva do professor/administrador (definição dos módulos de pergunta e resposta, acesso aos dados dos alunos); e o sistema que gerencia estes componentes (jogo, cadastro de perguntas e respostas, pontuação, acompanhamento do desempenho e avanço do aluno e interface Web).

Para chegar ao final do tabuleiro, o jogador precisa responder corretamente as perguntas que aparecem quando seu personagem se posiciona em uma casa demarcada. O jogo é, portanto, um misto integrando um jogo de tabuleiro e um jogo de perguntas e respostas (Quizz).

Alguns conceitos foram trazidos desse sistema original, dos quais pode-se citar: Sistema Web: é a porta de acesso para todas as funcionalidades do sistema, assumindo um papel ainda mais importante que no sistema anterior; Tabuleiro: o que antes era um tabuleiro específico para cada disciplina e ano escolar, agora é dinâmico e alguns parâmetros podem ser modificados pelo professor.

Assim, o desenvolvimento do novo sistema se iniciou com dois módulos independentes.

\subsection{Temática Escolhida}

De modo a despertar o interesse do jogador pelo jogo, tornando a história do jogo atrativa, foi utilizado o universo fictício de Atlantis. A cidade de Atlântida passou por um período de guerras e violência, portanto o "guerreiro", corrompido pelo poder, foi castigado e hoje existe o "guardião", o personagem principal controlado pelo jogador, que deve encontrar a sabedoria na escuridão.

A analogia da escuridão, que representa a ignorância, e da luz, que representa o conhecimento, é usada por todo tabuleiro, onde somente o personagem principal é iluminado, enquanto o restante do tabuleiro continua na escuridão.

O jogo de tabuleiro se inicia com a apresentação de uma curta história, como segue: "A escuridão só é perigosa se a luz não voltar." - dito popular Atlante. Contam nossos avôs que Atlântida era o continente mais respeitado de todo o planeta Terra.Possuía muitos recursos naturais e a tecnologia mais avançada. Porém, infelizmente, o Guerreiro que cuidava do continente se corrompeu na busca pelo poder e os Deuses nos castigaram, ocultando-nos do resto do mundo. Chamamos esse dia de "O Colapso". Depois que o primeiro Guerreiro foi destruído, criouse um Guardião. Ele armazenou os conhecimentos de toda a Atlântida, para poder cumprir a missão que os Deuses nos deram, e assim receber a luz de volta.

\subsection{Tabuleiro}

Foi utilizado do jogo anterior apenas o conceito de se adotar tabuleiros, pois toda a dinâmica foi re-projetada e implementada. A inspiração do novo tabuleiro se deu em jogos como HeroQuest, esse mesmo baseado em jogos de fantasia do tipo Role-Playing Game (RPG), que em português significa: "jogo de interpretação de personagens". O HeroQuest é, além de um jogo de tabuleiro, um sistema de jogos, onde o mestre de jogo cria os cenários que desejar com os elementos do jogo: o tabuleiro, mobiliário e monstros.

O novo tabuleiro segue a mesma ideia, porém ao invés de ter um "mestre de jogo", o tabuleiro é dinamicamente criado de acordo com parâmetros simples e elementos definidos pelo professor. Outra mudança em relação aos jogos de RPG foi a decisão adotada pela equipe de não usar a violência para representar a 
progressão no jogo. Assim, batalhas e armas não poderiam fazer parte do tabuleiro. Portanto ao invés dos calabouços do HeroQuest, foi escolhida a Lenda de Atlântida para representar o tema do tabuleiro, e vem disto o nome deste projeto: Ludo Educativo Atlantis.

\subsection{Mecânica}

Após a apresentação da história, o jogador "assume o papel de Guardião" e inicia o jogo já no tabuleiro, como pode ser observado na Figura 4, a seguir. Com um dado no lado inferior esquerdo, o jogador clica para descobrir quantas casas pode se movimentar, escolhendo seu caminho quando possível. Ao longo do tabuleiro o jogador poderá encontrar recompensas e desafios.

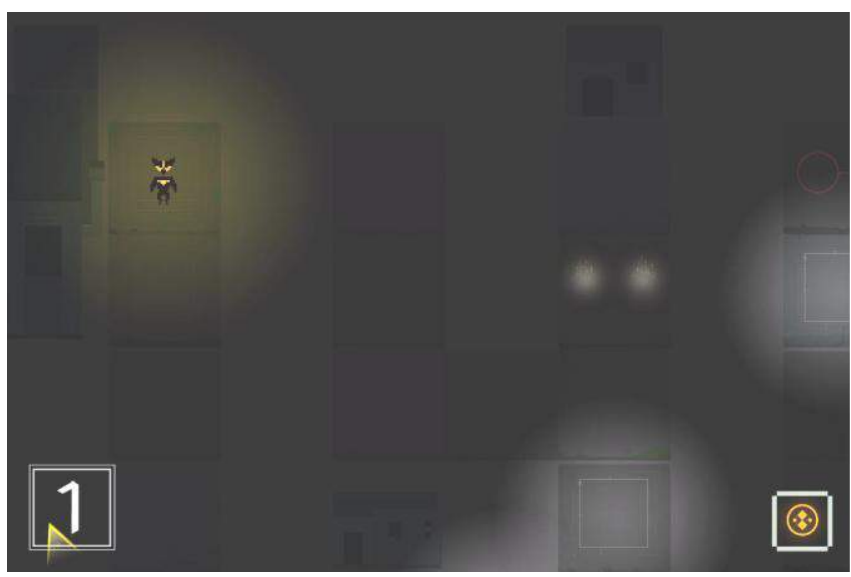

Figura 4 - Tela inicial do Tabuleiro

A cada desafio vencido o jogador recebe "prêmios" que podem melhorar seu desempenho geral no jogo, facilitando diversas situações.

\section{Sistema Web para gerenciamento do jogo}

O sistema Web é o portal de acesso e gerenciamento do jogo. Tanto alunos quanto professores devem acessar o portal para selecionar qual jogo deseja entrar ou para administrar seus alunos. Para isso foram utilizando alguns conceitos:

- Curso: generalização do conceito de disciplina e ano escolar. Um curso poderia ser definido como "Biologia do $5^{\circ}$ ano do Ensino Fundamental" tanto quanto "Curso de Inglês Básico", assim podendo ser usado em mais situação do que em matérias escolares.

- Dificuldade: parâmetro que irá influenciar diretamente na geração do tabuleiro, com valores de 0 (zero) a 100 (cem). $\mathrm{O}$ valor zero significa que o aluno pode errar todas as perguntas e ainda assim avançar de módulos, assim como cem significa que o aluno não pode errar pergunta alguma. Valores intermediários definem $o$ mínimo percentual de questões certas para avançar nos módulos, assim como dita a quantidade de desafios e o grau de dificuldade deles. O valor padrão é de $70 \%$.

- Privado: define se alunos podem participar desse curso sem estar em uma sala que possua o curso.

- Categorias: permite encontrar mais facilmente os cursos.

- Módulo: divisão dos cursos correspondendo a um jogo do tabuleiro, ou seja, a cada novo módulo, um tabuleiro será gerado novamente. Cada módulo possui um número não fixado de questões. Na sua concepção foi criado para dividir os cursos em bimestres ou trimestres escolares, permitindo a liberação de módulos pelo professor conforme o aluno vai evoluindo no curso. Porém essa divisão não é rígida e fica a critério do professor o que cada módulo representa, permitindo-o adaptar o jogo a sua realidade.

- Sala: permite agrupar diversos cursos e alunos em um só lugar. As salas foram criadas para modelar um ano específico de uma sala de aula, assim o professor pode disponibilizar uma lista de cursos a uma sala de aula de uma só vez. O acesso a essa sala de aula é restrito e depende do professor divulgar um código do sistema.

- Jogada: se inicia quando o usuário entra em um módulo para jogá-lo, portanto liga um jogador a um módulo. As questões em cada jogada devem ser únicas, ou seja, cada questão somente pode ser respondida uma vez. Em qualquer momento da jogada, sua pontuação ou nota será dada pelo número de questões corretas sobre o número de questões daquele módulo. A jogada termina quando todas as questões se esgotam ou quando o jogador abandona aquele jogo.

Foi utilizado o sistema de pacotes do Symfony 2, o qual permite desenvolver uma parte do site de forma modular e independente de outros pacotes. Além disso, se utilizou o suporte de ramificação do sistema de gerenciamento de versões Git $^{4}$ para criar um novo ramo de desenvolvimento do portal até que o código se tornasse estável suficiente para ser implantado no portal, sem atrapalhar os outros usuários.

Como o jogo se porta com um ramo novo no repositório do portal, foram adicionadas novas entidades à Base de Dados existente. As novas entidades desenvolvidas, tal como foram implementadas no projeto final.

A construção da interface do sistema Web se iniciou logo após a definição dos conceitos mais importantes do sistema Web. Sua concepção se iniciou com a criação de protótipos não funcionais. Essa primeira etapa foi realizada utilizando o framework de CSS chamado Bootstrap, utilizado em todo o portal.

$\mathrm{Na}$ implementação dos protótipos, eles foram importados da maneira que estavam, com dados estáticos de exemplo e aos poucos, conforme a lógica era implementada, os dados eram substituídos com dados dinâmicos do Banco de Dados. Isso permitiu ter uma visão geral do sistema desde o princípio e enxergar potenciais problemas desde o início do desenvolvimento do projeto.

A primeira tela desenvolvida para o sistema foi a interface inicial da Web, onde na mesma página haveria uma seção destinada ao aluno e uma destinada ao professor, onde com o tempo se tornou claro que as informações iriam poluir muito a tela e deveriam ser divididas em páginas separadas.

\section{APLICAÇÃO EM SALA DE AULA}

Durante o quarto bimestre do ano de 2014 foi feita a aplicação do jogo Atlantis na disciplina de Ciências no Ensino Fundamental (Ciclo 2) para duas turmas de sétima série na Escola Estadual Esterina Placco, na cidade de São Carlos-SP. Foram cadastradas oito questões e opções de resposta, incluindo algumas com a

${ }^{4}$ http://www.git-scm.com/ 
presença de imagens. Esse número relativamente pequeno de questões foi escolhido para que o jogo pudesse ser iniciado e terminado, com acompanhamento da docente, no prazo de duas aulas, uma hora e quarenta minutos.

A docente responsável pelo estudo de caso tem 26 anos de idade e trabalha na rede estadual de ensino de São Paulo há seis meses, como professora efetiva, porém, anteriormente, já exercia atividades de docência há um ano. Sendo assim, é uma professora estadual jovem com experiência 1 ano de meio de atividades.

A docente ainda é formada em Licenciatura em Ciências Exatas, com habilitação em Física e possui mestrado em Ciências na subárea de Física Aplicada, ambos pela Universidade de São Paulo (USP-São Carlos).

A seguir é apresentada uma entrevista feita com a docente sobre sua experiência.

- Você sente a necessidade de atividades que incluam jogos e outras que vão além da lousa, giz e livros convencionais? Porquê?

Acredito que uma boa dosagem entre os diversos recursos didáticos disponíveis torna a aula mais atrativa e favorece a aprendizagem de mais alunos. Aqueles que não gostam de desenhar, ou de ler ou de escrever, quando o professor usa um modelo, um jogo, uma figura ou um filme, podem se interessar mais pela matéria, o que não aconteceria usando apenas a lousa e giz. Além disso, a maioria dos alunos possui contato com celular, computador, ou tem interesse por tecnologia e acaba cobrando o professor para "fazer uma coisa diferente". Penso que quanto mais o aluno está interessado em aprender, menos problemas com indisciplina e violência vivenciaremos em sala de aula, o que facilita tanto o trabalho do professor quanto a aprendizagem do aluno.

- Qual projeto/pesquisa você realizou com os alunos? Quais jogos? Em quanto tempo?

Durante o quarto bimestre do ano de 2014 trabalhei o assunto energia elétrica, o que envolve o entendimento de vários conceitos abstratos como: o elétron, eletrização, corrente elétrica entre outros. Assim, as aulas iniciais eram carregadas de conceitos, e percebi que poucos alunos tinham se interessado pelo assunto.Na sequência, realizei com eles o experimento clássico de eletrização com uma caneta e pedaços de papel, e a resposta foi imediata: empolgação e repetição do experimento com outros alunos de outras salas. Na sequência, após algumas aulas, visitamos a sala de informática para pesquisarmos sobre raios e notei que eles tinham gostado da atividade, mas não a maioria (alguns fizeram somente porque tinha que fazer). Em outros momentos da disciplina já tinha jogado um jogo de dicas que eu mesma criei sobre astronomia e também tínhamos visitado a sala de informática para jogar um jogo sobre os planetas, chamado de Jogo do Sistema Solar do Cambito, ${ }^{5}$ que eles gostaram também. Quando conheci o Atlantis, logo senti vontade de usar com os alunos, mas minha primeira experiência foi um pouco traumática, pois neste público, muitos (a maioria) não sabem utilizar e-mail ou não tinham nenhuma conta de e-mail, então o cadastro dos alunos foi um pouco delicado. Decidi que iria usar o jogo como forma de avaliar os alunos.Assim, apliquei o jogo durante duas aulas (1h40min) e cada aluno se sentou em um computador e foi explorando o jogo individualmente.

\footnotetext{
${ }^{5}$ http://www.cambito.com.br/games/solar.htm
}

- Você usou algum formulário de consentimento com os alunos ou pais?

Antes de aplicar o jogo com as turmas, fiz um convite para alguns alunos, para que viessem no laboratório testar o jogo. Neste caso, pedi autorização dos pais por escrito, $e$ compareceram duas alunas.

- Como foram as atividades com os alunos? Quantos participaram?

Participaram 21 alunos. Durante a atividade eles ficaram empolgados e muito interessados pelos jogos. E alguns que normalmente não prestavam atenção nas aulas, tentaram jogar o jogo até conseguir acertar $100 \%$ das perguntas, o que me deixou bem satisfeita.

- Os alunos preencheram alguma ficha? Foi opcional? Se sim, quais resultados foram obtidos?

Nos últimos dias de aula, pedi para quem quisesse avaliar a disciplina, fazer em uma folha separada um comentário sobre o que mais gostou na matéria de ciências.

- O que os alunos acharam da interface do Atlantis? Eles gostam de jogos de tabuleiros?

Pelo que pude observar, eles gostaram mais do personagem raposa. Aparentemente tiveram dificuldade em alguns momentos para localizar a chave necessária para desbloquear a esfinge, $e$ praticamente não utilizaram o inventário presente no jogo.

\section{- O professor conseguiu visualizar os resultados?}

Em minha área no site pude acompanhar os resultados de cada aluno, quantas vezes ele jogou, quantas perguntas ele acertou em cada jogada, e quanto tempo ele levou para completar cada jogada.

- Os alunos se mostraram interessados nas questões ou assuntos que desconheciam? $O$ jogo Atlantis estimulou a busca por conhecimento para que o aluno tivesse um bom resultado?

Nas aulas após a aplicação do jogo, alguns alunos disseram que a atividade tinha sido muito legal, mas que as questões estavam difíceis. Mas, também pude perceber que o interesse deles pelas aulas havia aumentado, pois estavam prestando mais atenção $e$ fazendo as tarefas que eram passadas, participando, saneando dúvidas... por isso acredito que as questões do jogo despertaram a curiosidade deles.

- Houve algum tipo de competição entre os alunos? Essa competição entre os alunos (caso tenha existido) foi saudável?

Sim. Eles escolhiam o mesmo personagem (a maioria preferiu a raposa), e ficavam disputando nos mini games. No final da aula, os que tinham finalizado o jogo e completado o jogo ficavam conversando com os demais e falando sobre o jogo, de forma empolgada.

- Você pretende continuar usando jogos como o Atlantis na sala de aula?

Pretendo. Sempre que for possível usarei esse jogo.

- Em sua opinião como os jogos podem ser construídos para otimizar a busca de conhecimento pelos alunos.

Acredito que os jogos tem que ser planejados de forma que não saturem o aluno com conteúdos carregados e que despertem algum sentimento bom nos alunos: de felicidade por uma recompensa ganha, de vitória por ter cumprido um desafio... Eles têm que durar no máximo duas aulas, para que o aluno consiga 
“concluir a missão", pois a ida dos alunos várias vezes na sala de informática pode se tornar um problema, no sentido de conseguir agendamento e do distanciamento entre uma atividade e a outra. Além disso, o jogo tem que ter para o aluno, uma relação direta e explicita com a matéria que está sendo vista em sala de aula, isso para públicos escolares, mas sem perder o fator diversão. $O$ jogo perfeito seria aquele que vicia, que ensina um conteúdo, procedimento ou uma atitude, e que diverte.

\section{CONCLUSÃO}

Neste trabalho foram apresentadas considerações e resultados da criação de uma abordagem de avaliação com uso do Ludo Educativo Atlantis, um jogo interativo de tabuleiro integrado a um rico sistema de cadastro e acompanhamento de respostas às questões. Enquanto que existem outros Jogos Educacionais, são raros aqueles que permitem que o aluno, junto com o professor, possam criar sua própria jornada. Desse modo há o avanço aqui relatado nessa característica de flexibilidade do sistema criado, que irá permitir que educadores criem laços maiores com seus alunos, que irão trabalhar de modo interativo em questões customizadas.

O sistema demonstra grande potencial para a utilização tanto salas de aula como lições de casa, por professores e educadores de todas as disciplinas e escolaridades. O interesse por parte dos professores parceiros com o qual foi compartilhada a visão do sistema tem sido excelente.

Como próximo passo deste trabalho tem-se como meta realizar o lançamento oficial do jogo para uso em escolas de todo o país, para tanto será feita uma cerimônia e convidadas autoridades, professores de escolas alvo do projeto e representantes de órgãos de imprensa.

Com a disseminação do uso do jogo, acredita-se que esse projeto será referência com o potencial de auxiliar significativamente profissionais da área de educação, ao permitir que suas aulas e lições de casa se tornem uma tarefa muito mais prazerosa, com relatórios sintetizados para o professor.

\section{AGRADECIMENTOS}

Os autores agradecem às instituições de fomento FAPESP, CNPq e FAPEG, pelo suporte financeiro concedido, às universidades UNESP, USP, UFG e UFSCar pelo apoio institucional incluindo interação com seus Programas de Pós-Graduação e a todos os usuários que colaboraram voluntariamente para execução deste trabalho.

\section{REFERÊNCIAS}

[1] Crawford, C. The Art of Digital Game Design, Washington State University, Vancouver, 1982.

[2] Lucchese, F., Ribeiro B. (2012). Conceituação de Jogos Digitais. Universidade Estadual de Campinas.
[3] McClarty, K. L.; Frey, P. M. e Dolan, R. P. A Literature Review of Gaming in Education Research Report. n. June, 2012.

[4] Runenson, P. e Höst, M. Guidelines for conducting and reporting case study research in software engineering. Empirical Software Engineering., 14 (2):131-164, 2009.

[5] Juul, J. A Clash Between Game and Narrative. Proceedings of Digital Arts and Culture Conference, Bergen, Norway, 1998.

[6] Bergervoet, E. et al. Let the Game Do the Talking: The Influence of Explicitness and Game Behavior on Comprehension in an Educational Computer Game. Proceedings of International Conference on Cyberworlds 2011, p. 120-127, doi:10.1109/CW.2011.30, 2011.

[7] Aguilera, M. D. E. e Méndiz, A. Video Games and Education (Education in the Face of a "Parallel School "). v. 1, n. 1, p. 1-14, 2003.

[8] Aranda, D. e Sanchez-Navarro, J. Understanding the use of video games in non-formal education in Barcelona. Proceedings of International Conference on Advances in Computer Entertainment Technology, p. 385-388, 2008.

[9] De Figueiredo, Nébia Maria Almeida. Método e metodologia na pesquisa científica. 3ed. ed. [S.1.]: São Caetano do Sul (SP), 2008. ISBN 9788577280858, p. 1-247.

[10] Franzwa, C. et al. Serious Game Design: Motivating Students through a Balance of Fun and Learning. 2013.

[11] Girard, C., Ecalle, J., \& Magnan, A. (2013).Serious games as new educational tools: how effective are they? A meta-analysis of recent studies. Journal of Computer Assisted Learning, 29(3), 207-219.

[12] Hamari, J.; Koivisto, J. e Sarsa, H. Does Gamification Work? Literature Review of Empirical Studies on Gamification.2014 47th Hawaii International Conference on System Sciences, p. 3025-3034, doi:10.1109/HICSS.2014.377, 2014.

[13] Moratori, Patrick. Por que Utilizar Jogos Educativos no Processo de Ensino Aprendizagem?. Trabalho de Conclusão de Curso - UFRJ, 2003.

[14] Mouaheb, H. et al. The Serious Game: What Educational Benefits? Procedia - Social and Behavioral Sciences, v. 46, p. 5502-5508, doi:10.1016/j.sbspro.2012.06.465, 2012.

[15] Vianna, M. et al. Gamification, Inc. Como reinventar empresas a partir de jogos. e-book ed. Rio de Janeiro: MJV Press, 2013. p. 116. 